\title{
X-Ray CT inspection of subsurface areas of concretes exposed to fast flowing liquids
}

\author{
Libor Sitek, Petr Hlaváček, Kamil Souček \\ Academy of Sciences of the Czech Republic, Czech Republic \\ Lenka Bodnárová \\ Brno University of Technology, Czech Republic \\ Josef Foldyna, Vendula Zajícová, \\ Andrea Berčáková, Vladimír Foldyna \\ Academy of Sciences of the Czech Republic, Czech Republic
}

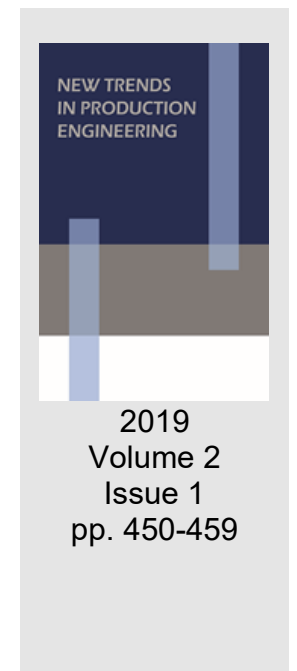

Date of submission to the Editor: 05/2019

Date of acceptance by the Editor: 08/2019

\section{INTRODUCTION}

Concrete surfaces affected for a long time by flowing liquids are exposed to a combination of several degradation processes. Gradual erosion of the surface layers is caused not only by the abrasion, but also by the effects of chemical and bacterial impacts. In addition, cavitation occurs at higher fluid flow rates. While the erosion is caused by small particles in the flow, such as mud, sand, gravel, ice or various debris, cavitation is a result of the collapse of vapor bubbles formed due to pressure changes in the fast flowing liquid flow. Thus, the concrete surface becomes porous, which further deteriorates its erosion resistance. All these processes act mostly simultaneously and cannot be separated from each other. An advantage of the aforementioned degradation mechanism for concrete structures is the relatively slow disintegration rate of the surface layers, whereas it is an obstacle to the rapid and plausible prediction of concrete behavior. Visible deterioration can occur within some months, more often, though, after several years or decades. Moreover, the deterioration happens irregularly, generally in spurts depending on the actual amount of liquid and its speed (heavy rains, floods, etc.).

The resistance of concrete to the degradation by flowing fluids is determined by a number of factors, the most significant of which is the composition of the concrete, curing conditions, physical and mechanical properties, presence and type of additives (fibers, fly ash, etc.) and, in particular, the concrete surface finish and environmental conditions when using the concrete structure. Preparing the "appropriate" concrete mixture resistant to the flowing fluids and determining its fundamental properties is a prerequisite for ensuring the long lifetime of hydraulic structures (spillways, stilling basins, walls of upstream reservoir, drain pipes, hydraulic tunnels etc.). Due to the slow process of degradation, difficulties arise if the resistance of a particular concrete mixture is verified in real conditions. Computational modeling of a comprehensive process 
of concrete deterioration is very difficult, including the correct determination of initial and boundary conditions. One alternative is the application of standardized experimental methods or targeted testing which is usually focused only on one of the degradation mechanisms (for example American Concrete Institute, 1998; American Society for Testing and Materials, 2002; Horszczaruk, 2009; Horszczaruk, 2004) and often takes inordinately long time (Binici et al., 2009). Leaving the effects of chemical or biological degradants aside, the so-called high-speed water flows represent a promising (Hlaváček et al., 2019) and relatively popular (Momber et al., 1999; Hu et al., 2002; Momber, 2016; Momber, 2017) method to simulate the flow of frequently contaminated liquids with high or low amount of free hard particles of different sizes. The pressure energy of a liquid changes into the kinetic energy and the velocity of the liquid exiting the water nozzle can reach up to hundreds of meters per second. The interaction of the flow with the concrete surface causes the same degradation mechanisms that occur in real concrete structures. Alternative admixture of abrasive particles in the high-speed water flow may further improve the disintegration process. The erosion is rapid and real erosion processes can be thus faithfully simulated with an appropriate combination of flow parameters and test setting (Sitek et al., 2018).

The appearance and topography of the resulting concrete surface after exposure to flowing liquids and the investigation of the amount of removed material in real as well as in simulated processes are the basic evaluation methods for assessing the resistance and durability of concrete structures. The understanding of the situation under the concrete surface (the presence of pores, fractures, cracks and other inhomogeneities) then contributes to deepening the knowledge of acting processes and their impacts on the overall condition of the concrete. The micro X-Ray Computed Tomography (micro XRay CT) method has proven to be a perfect non-destructive laboratory tool for the inspection of subsurface structures. The method enables the analysis of changes of the same sample (Sitek et al., 2015) after exposure to external loadings (mechanical, thermal, chemical, etc.). In this way, some structural states that could be wrongly determined to be caused by a particular loading can be excluded.

The X-Ray CT method was used for the inspection of subsurface structures of concretes exposed to the action of a pure high-speed water flow and a highspeed water flow with addition of abrasive particles. It was examined whether the simulation of effects of flowing fluids could cause changes in subsurface layers of concrete.

\section{SIMULATION METHOD AND EXPERIMENTAL SETUP}

In order to simulate the process of the concrete surface treatment by flowing liquids, a well-established method of loading by a high-speed water flow acting perpendicular to the surface to be investigated and moving along a predetermined trajectory was used (Hlaváček et al., 2019a). The reason was to affect a larger area of concrete, since the diameter of the flow used was only 1 
$\mathrm{mm}$. One impact cycle consisted of two mutually perpendicular zig-zag trajectories (see Fig. 1).

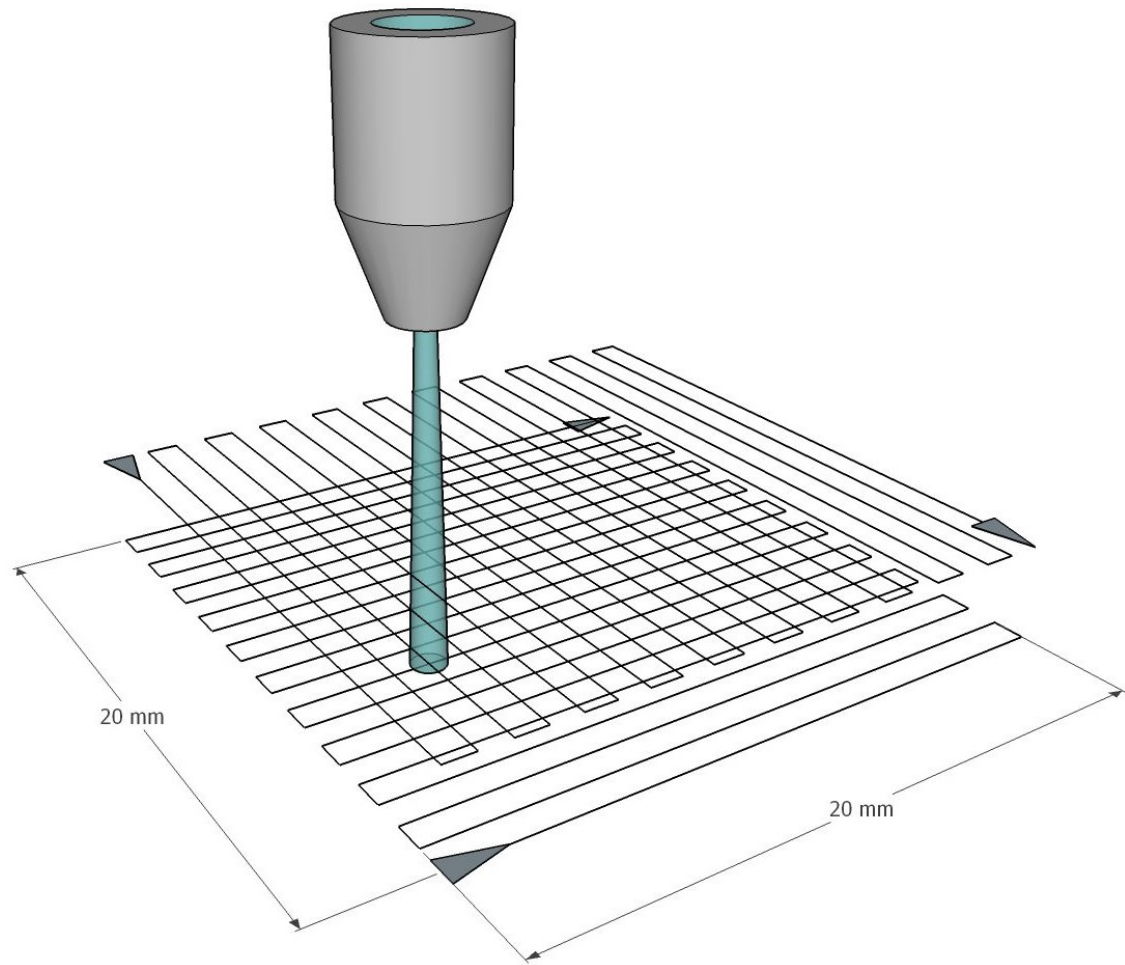

Fig. 1 Complex trajectory for one erosion cycle during the concrete surface treatment by the high-speed water flow

The perpendicular impact of the water flow can be associated with the real case of the impact of water on the bottom of a dam stilling basin. Previous research has already revealed that in order to make the simulated situation as close as possible to the real situation, low impact velocities and low amount of fine abrasives in case of the water flow with abrasive particles should be used (Hlaváček et al., 2019b).

The high-speed water flow was generated using a conventional SLICE I cutting head with the water nozzle diameter of $0.33 \mathrm{~mm}$, focusing tube diameter of 1.02 $\mathrm{mm}$ and focusing tube length of $76.2 \mathrm{~mm}$ which is usually used for abrasive water jet machining. During experiments, the water flow parameters were set as follows: water pressure upstream the water nozzle - $80 \mathrm{MPa}$ (pure water flow) and $40 \mathrm{MPa}$ (abrasive water flow), distance from the exit of the focusing tube to the specimen surface $-50 \mathrm{~mm}$. The impact angle of the flow was set perpendicular to the concrete surface. The traverse velocity of the flow above the concrete surface was set at $500 \mathrm{~mm} \cdot \mathrm{min}^{-1}$. During experiments with the flow consisting of a mixture of water and abrasive grains, Australian garnet GMA of the grain size of $80 \mathrm{MESH}$ with the mass flow rate of $20 \mathrm{~g} \cdot \mathrm{min}^{-1}$ was used.

Concrete testing specimens were cut off a concrete shaft unit (nominal size diameter of $800 \mathrm{~mm}$, internal height of $500 \mathrm{~mm}$ and wall thickness of $80 \mathrm{~mm}$ ) by the abrasive water jet in order to facilitate the manipulation and consequent measurements. Cylindrical specimens with a diameter of $30 \mathrm{~mm}$ and a height of 
$80 \mathrm{~mm}$ were tested. Selected properties of the concrete shaft unit are presented in Table 1.

Table 1 Properties of concrete shaft unit

\begin{tabular}{|l|c|}
\hline \multicolumn{1}{|c|}{ Parameter } & Value \\
\hline Crushing load $\left[\mathrm{kN} \cdot \mathrm{m}^{-1}\right]$ & 57.9 \\
\hline Concrete water absorption [\%] & 3.9 \\
\hline Concrete compressive strength [MPa] & 64.5 \\
\hline Concrete density $\left[\mathrm{kg} \cdot \mathrm{m}^{-3}\right]$ & 2300 \\
\hline
\end{tabular}

Subsurface structures of the examined concrete specimens were investigated using micro X-ray CT scanner XT H 225 ST by Nikon Metrology. To obtain 3D CT volume of analyzed specimens, $31412 \mathrm{D}$ radiographic projections of a tested specimen at a known angle during one full turn of the specimen were scanned. The exposition time of one radiographic projection was $16 \mathrm{~s}$ consisting of four radiographic frames (4 $\mathrm{s}$ each). The edge size of individual cubic voxels in the 3D CT volume is approximately $17 \mu \mathrm{m}$. VG Studio Max v. 2.2 software was used for the CT data analysis. At first, concrete specimens were scanned prior to the treatment by the pure or abrasive water flow. After the flow treatment and erosion of surface layers, the same concrete samples were re-scanned and comparative CT scans were generated in order to evaluate the effects of the impacting and flowing liquid on the integrity of the inner concrete structure. The volume analyzed was localized in the central area of the scanned test specimens to eliminate the effects of external boundary conditions. Edge parts of test specimens may be excessively disintegrated due to the loss of aggregates and cement binder, which could negatively affect the results due to extreme loading by the simulating flow. Corresponding CT volumes scanned before and after the flow loading were dimensionally oriented in a way that the tomographic cross-sections with identical position could be simultaneously compared and the effects of fast flowing liquids evaluated.

\section{RESULTS AND DISCUSSION}

Fig. 2 shows the computational reconstruction of the original surface, the surface loaded by the pure high-speed water flow and the surface after exposure to the water flow with abrasive particles. All of the following findings are illustrated by CT scans of the original structure of concrete specimens and CT scans of concrete specimens after the application of the high-speed water flow, either pure or with abrasives.

Surfaces loaded by a water flow without abrasive particles and a water flow with abrasive particles differ significantly. This is due to a different mechanism of erosion of surface layers. The pure flow causes local erosion of the hardened cement paste in particular. The hardened cement paste is then carried along the surface by the water flow. Erosion is caused by shear forces and local cavitation as the liquid flows over the uneven concrete surface. 

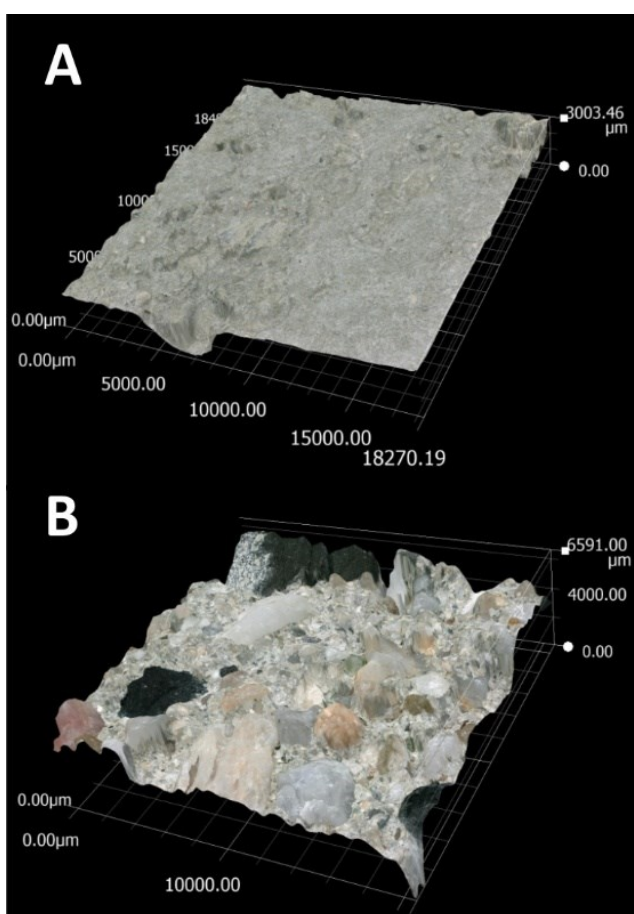

20000.00

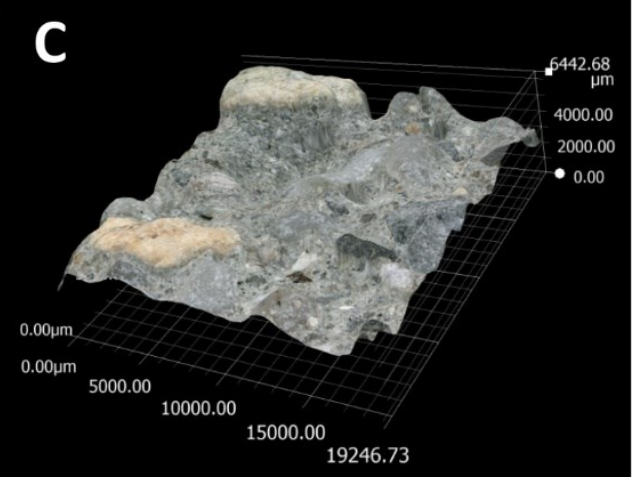

Fig. 2 Computational reconstruction of the original concrete surface (A), surface after exposure to the pure high-speed water flow (B) and the surface after exposure to the water flow with abrasives (C)

If the shear forces exceed the adhesion between the aggregate and the cement, a grain of the aggregate is released and moved by the water flow along the surface, further increasing the erosion capacity of the flow. The aggregate that was not released from the cement matrix is exposed and revealed from the resulting surface (see Fig. 3).
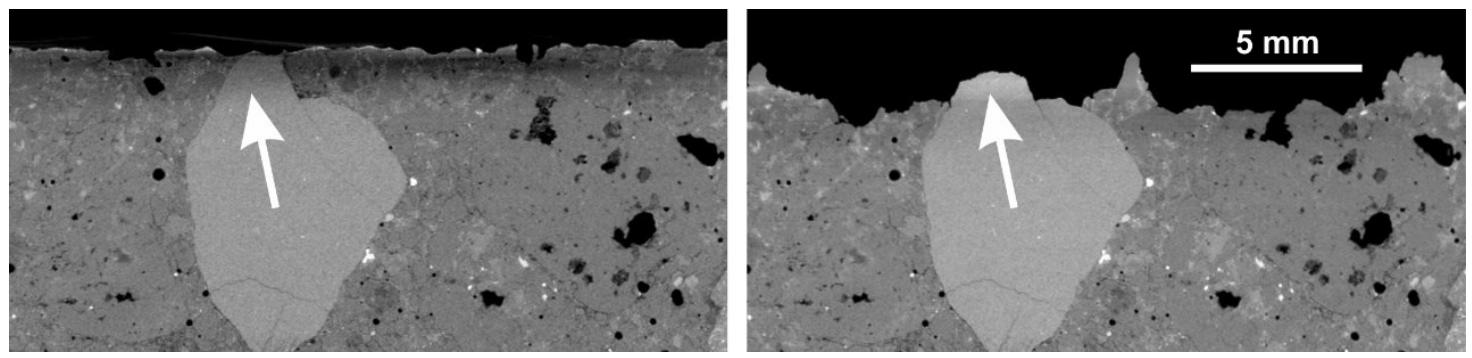

Fig. 3 Comparison of the original surface (left) and the newly created surface after the treatment by the high-speed water flow without abrasives (right); it is evident that the aggregate grain is exposed after the flow application 
If some structural elements (e.g. aggregate) already contained fractures or cracks, they were enlarged due to the high-pressure water penetration (Fig. 4).
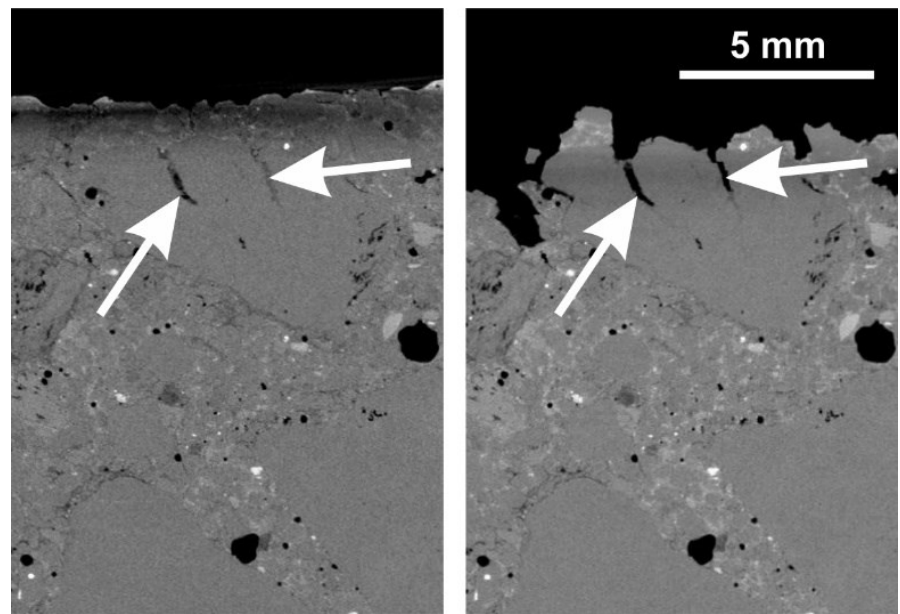

Fig. 4 Cracks in the aggregate enlarged by the impact of the high-speed water flow on the surface (left - the original structure, right - the structure after the treatment by the water flow without abrasive particles)

Fig. 5 clearly shows the state after the water penetrated between the cement matrix and the aggregate grain and formed a separation crack. The grain was not removed from the structure, but further flow of water would cause loosening of the grain. The impact of original fractures in the aggregate on new surface formation is also evident (see the grain surface of the fine-grained greywacke aggregate on the left side of both images).
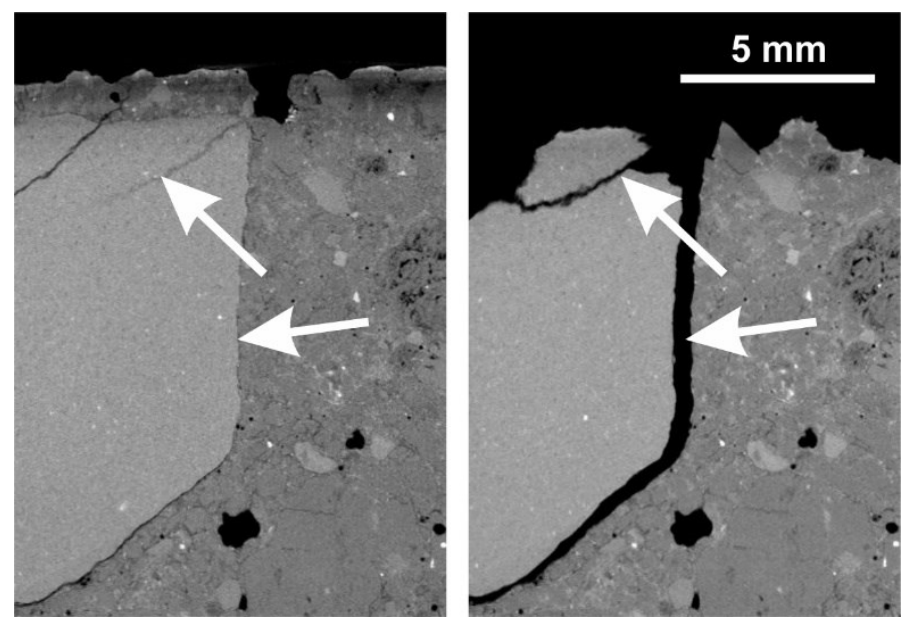

Fig. 5 Formation of a separation crack between the aggregate and the cement matrix (left - the original structure, right - the structure after the treatment by the water flow without abrasive particles)

When using the flow with abrasive particles, the erosion effect is several times higher even in the case of lower flow impact velocity (caused by lower water pressure upstream the water nozzle during flow generation) compared to pure water flow. After the interaction with the surface, abrasive grains are carried by the flow along the surface. When interacting, the grains can be broken down into smaller particles that become part of the liquid flow together with free grains of the hardened cement paste and smaller aggregate. In addition to the previous 
phenomena, higher amount of the abrasive material in the flow causes local disintegration of the aggregate surface that is revealed from the newly formed surface and often leads to aggregate particle amputation (Fig. 6).
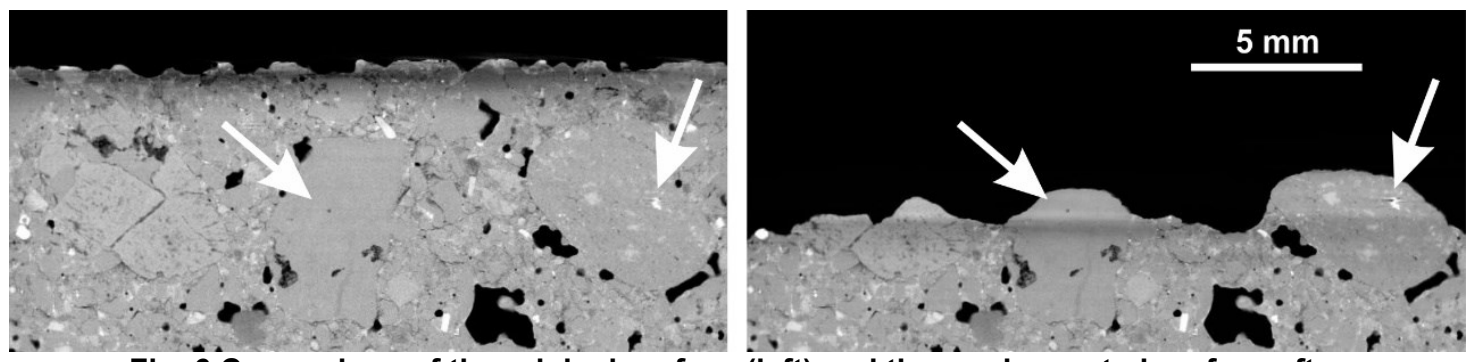

Fig. 6 Comparison of the original surface (left) and the newly created surface after the treatment by the high-speed water flow with abrasives (right); amputation and smoothening of aggregate grains is visible after the application of the flow

Due to the increased surface loading, aggregate grains are more frequently extracted from the cement matrix and thus more material is removed. Compared to the surface after the application of the water flow without abrasives, the occurring abrasion causes surface smoothing, as is the case with the real effects of the fast flowing contaminated liquids and the surface profile appears to be less rough and more wavy (compare Fig. 3 and Fig. 6). Surfaces of internal pores existing in the original structure can become part of the newly created surfaces (see Fig. 7).
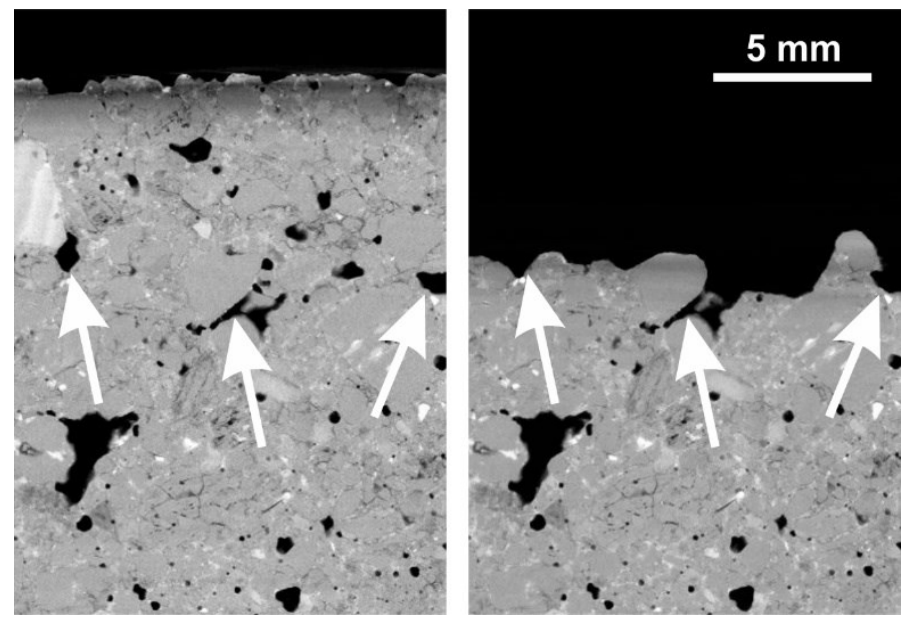

Fig. 7 Detail of the newly created surface exploiting the original pore structure of the concrete (left - the original structure, right - the structure after the treatment by the water flow with abrasives); after the erosion, the original surfaces of some pores become part of the newly created surface

Detailed inspection of subsurface structures confirmed previous findings (Klich et al., 2013) that the high-speed water flows (without and with abrasives) used for simulations do not damage areas below the concrete surface. The effects of water flows do not cause initiation of new fractures, cracks or other inhomogeneities that could adversely affect the final strength of the concrete and cohesion of concrete structural elements (Figs. 3-7).

The relative amount of concrete removed by the pure and abrasive water flow per unit of the loaded area is shown in Fig. 8. 
6.00

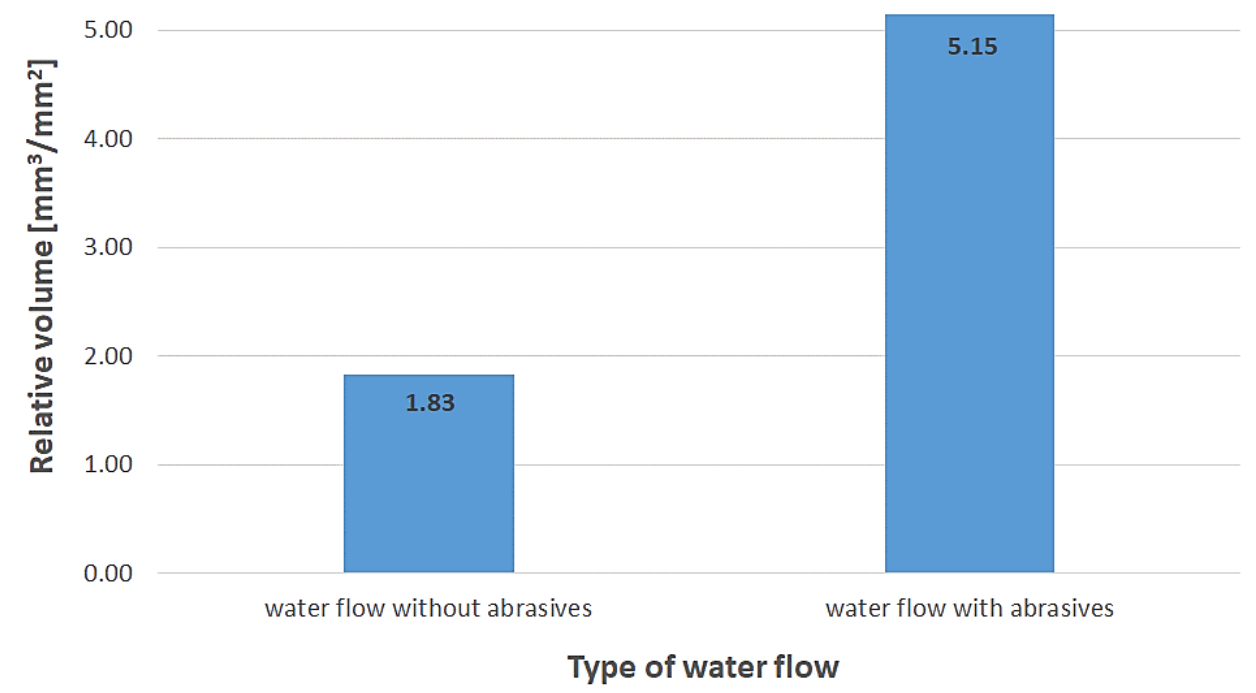

Fig. 8 Average relative values of the volume of concrete removed by high-speed water flows without abrasive (water pressure of $80 \mathrm{MPa}$ ) and with abrasive (water pressure of $40 \mathrm{MPa}$ )

It is obvious that during the mechanical simulation of concrete deterioration by fast flowing fluids, the abrasive water flow removes approximately 3 times more concrete than the water flow without abrasive particles (under testing conditions specified in Chapter 2). The value was calculated as the average of all tested concrete specimens (comparing the original volume of specimens and the volume after the loading by the water flows). The difference in the amount of material removed depending on the flow used is also evident from various depths of erosion and creation of new surfaces (compare, for example, Fig. 4 and Fig. 7).

\section{CONCLUSION}

The subsurface structures of cement composites were studied using the micro X-Ray CT methods. It has been shown that after the perpendicular loading of concrete surfaces by the simulating high-speed water flows without and with abrasive particles, the internal structure of concretes is not additionally damaged and new fractures or cracks are not initiated. However, the high-pressure water can penetrate the already existing fractures and pores and they can be further used during the erosion process and creation of new surfaces.

The new surfaces created by the pure water flow without abrasives differ significantly from the surfaces created by the abrasive water flows. While the water flows without abrasives mainly remove the cement stone and the aggregate grains are consequently revealed from the newly created surface, the abrasive water flows disintegrate the concrete in greater depths, remove and wash out the cement including the aggregate. The aggregate grains that remain in the cement matrix are often broken up by the flow and smoothened by further water flowing. The erosion process is very similar to the real situation of the impact and fast flowing of polluted liquids over the surface of hydraulic concrete structures and buildings. 
Based on the so-far obtained knowledge and previous research, it can be stated that the application of high-speed water flows on the concrete surface is a suitable and quick method for simulating the erosion wear of concretes exposed to the effects of fast flowing liquids.

\section{ACKNOWLEDGEMENT}

This work was supported by grant of the Czech Science Foundation (1825035S), by project of the Institute of Clean Technologies for Mining and the Utilization of Raw Materials for Energy Use - Sustainability program, reg. no. L01406 financed by the Ministry of Education, Youth and Sports of the Czech Republic and by project for the long-term conceptual development of research organisations RVO: 68145535. The authors are very thankful for the support.

\section{REFERENCES}

Concrete in Hydraulic Structures. In ACI Committee 210 Report.

American Society for Testing and Materials (2002). ASTM C 1138-97. Standard test method for abrasion resistance of concrete (underwater method), in: Annual Book of ASTM Standards, vol. 04.02, ASTM, West Conshohocken.

Horszczaruk, E. K. (2009). Hydro-abrasive erosion of high performance fiber-reinforced concrete. Wear 267, pp. 110-115.

Horszczaruk, E. K. (2004). Abrasion resistance of high strength fibre-reinforced concrete. 6th RILEM Symposium on Fibre-Reinforced Concretes - BEFIB 2004, Varenna, Italy.

Binici, H., Aksogan, O., Gorur, E. B., Kaplan, H., Bodur, M. N. (2009). Hydro-abrasive erosion of concrete incorporating ground blast-furnace slag and ground basaltic pumice. Construction and Building Materials 23, pp. 804-811.

Hlaváček, P., Sitek, L., Hela, R., Bodnárová, L. (2019a). Erosion Test with High-speed Water Jet Applied on Surface of Concrete Treated with Solution of Modified Lithium Silicates. In: Advances in Manufacturing Engineering and Materials. Lecture Notes in Mechanical Engineering, Basel: Springer Nature Switzerland AG 2019, pp. 135-143. Available at: https://link.springer.com/chapter/10.1007/978-3319-99353-9 15.

Momber, A. W., Mohan, R. S., Kovacevic, R. (1999). On-line analysis of hydro-abrasive erosion of pre-cracked materials by acoustic emission. Theoretical and Applied Fracture Mechanics 31, pp. 1-17.

Hu, X.G., Momber, A.W., Yin, Y.G. (2002). Hydro-abrasive erosion of steel-fibre reinforced hydraulic concrete. Wear 253, pp. 848-854.

Momber, A. W. (2016). A probabilistic model for the erosion of cement-based composites due to very high-speed hydro-abrasive flow. Wear 368, pp. 39-44.

Momber, A. W. (2017). Effects of erodent flow energy and local exposure time on the erosion of cement-based composites at high-speed hydro-abrasive flow. Wear 378-379, pp. 145-154.

Sitek, L., Hlaváček, P., Bodnárová, L. (2018). Use of high-speed water flows for accelerated mechanical modelling of erosive wear of concrete surfaces. In: MATEC Web of Conferences 244, 02007 (2018). Innovative Technologies in Engineering Production (ITEP'18), Bojnice, Slovakia. Available at: https://doi.org/10.1051/matecconf/201824402007.

Sitek, L., Bodnárová, L., Souček, K., Staš, L., Gurková, L. (2015). Analysis of Inner Structure Changes of Concretes Exposed to High Temperatures using Micro Xray Computed Tomography. Acta Geodynamica et Geomaterialia, Vol. 12, No. 1 (177), 79-89.

Hlaváček, P., Sitek, L., Klichová, D., Bodnárová, L. (2019b). Effects of abrasives during the accelerated simulation of mechanical corrosion of cement-based composites 
using the abrasive water flow. Acta Polytechnica CTU Proceedings, Vol. 22 (2019). In print.

Klich J., Hlaváček, P., Ščučka, J., Sitek, L., Foldyna, J., Georgiovská L., Souček, K., Staš, L., Bortolussi, A. (2013). Processing and finishing of granite surfaces. MONOGRAFIA Nowoczesne metody eksploatacji węgla i skał zwięzłych. AGH, Kraków 2013, pp. 36-43.

\begin{abstract}
.
Concrete structures affected for a long time by flowing liquids are exposed to gradual erosion in surface layers caused by a combination of several degradation processes: abrasion, cavitation and chemical or bacterial impacts. Due to the complex phenomena and difficult-todefine initial and boundary conditions, the whole process cannot be easily simulated using the conventional computing tools. Laboratory experimental research is thus the most appropriate approach for the investigation of a suitable composition of concrete resistant to the flowing liquids. However, the methods used are often very time consuming and last even several years. High-speed water flows can be elegantly used for the acceleration of the mechanical simulation of a real situation. Several experiments on the effects of the high-speed water flows on concrete surfaces have been carried out. Using the X-Ray CT methods, subsurface structures of concretes exposed to the accelerated mechanical simulation of the erosion wear caused by fast flowing liquids were investigated and presented in the article. It has been shown that the simulation does not cause initiation of new fractures or cracks in the original concrete structure. The pure water flow mainly removes the hardened cement paste and reveals the aggregate grains. The water flow with abrasive particles disintegrates in greater depths and washes out entire aggregate grains, eventually amputates them and finally smoothens entire surface.
\end{abstract}

Keywords: erosion, concrete, fast flowing liquid, high-speed water jets, X-Ray CT 